\title{
Characterized the Microalgae (Chlorella and Spirulina) and Macro Algae by Using TGA and Bomb Calorific Meter for the Biomass Energy Application
}

\author{
An-Peng Chen ${ }^{1}$ and Shuichi Torii ${ }^{2}$ \\ 1. Graduate School of Science and Technology, Kumamoto University, Kumamoto 860-8555, Japan \\ 2. Department of Advanced Mechanical Systems, Kumamoto University, Kumamoto 860-8555, Japan
}

\begin{abstract}
Biomass usually is noticed a composition of various types of waste materials that can be utilized as useful form of energy alternative to the conventional fossil fuels. However, this new kind of energy has not met its full potential in production of energy, especially electricity generation due to its lower performance in terms of thermal efficiency. Algae (included Microalgae \& Macroalgae) are widely used for multi-application developments such as fishery aquaculture, food/nutrient supplement, cosmetics, and biomass energy. Microalgae have been treated as the source of bio-fuel. In this paper, we selected the two types of freshwater microalgae “Chlorella Vulgaris" \& "Spirulina” and macro algae (Laminariaceae) as the main materials and we analyzed TGA (thermal gravity analysis) and calorific values (heat of combustion). We found the calorific values are 1,000-5,000 KC/KG and TGA results show that the microalgae decrease rapidly after reached $300{ }^{\circ} \mathrm{C}$. The results in this paper will be used as a reference material for microalgae multi-oriental energy application and biomass composition proximate and ultimate research development in the future.
\end{abstract}

Key words: Biomass energy, microalgae, TGA (thermal gravity analysis), combustion.

\section{Introduction}

Since the industrial revolution, the usage of fossil fuel, such as gasoline, coal, diesel and natural gas, had raised rapidly. Within the artificial activities and modernized industry not only consume huge quant of fossil fuel, but also increase the emission of $\mathrm{CO}_{2}$ to the atmosphere in the period of time. Global warning and climate change are very serious environmental topics in this decade. Reducing the emission of $\mathrm{CO}_{2}$ and finding alternative energy source become important issues now. Cleaning energy resource and reducing the $\mathrm{CO}_{2}$ emission are serious issues for the 21st century. After "Kyoto Protocol”, the assignment for reducing $\mathrm{CO}_{2}$ emission in 1997, the renew energy seems to become the solution which people are looking for [1]. Renewable energy includes wind, solar, OTECs, ocean current and biomass energy.

Corresponding author: An-Peng Chen, Ph.D. student, research fields: biomass energy application and microalgae engineering.
Biomass is a composition of various types of waste materials that can be utilized as useful form of energy alternative to the conventional fossil fuels. Biomass energy is not only a green technology, but also a renewable energy source that can replace coal quickly and cost-effectively, providing the same operational benefits while dramatically improving the environmental profile of energy generation. As an energy source, biomass can either be used directly, or converted into other energy products such as biofuel. Biomass energy with the mature technology has become wildly use in developing countries for decades, and contains various biomass materials such as woods, agricultural waste, animal grease, etc. Besides that, biomass energy has greater potential with multi-applications and more sustainability than other renewable energy. The 1st and 2nd generation biofuel that are made by corn, soybean and cellulose, are environmental friendly but might damage the food system and cause food crisis. Therefore with the 
alternative biomass material source, the 3rd generation biofuel uses microalgae that mainly formed lipid, proteins and cellulose, is the major material and is much different from its feedstock a crop food [2].

The algae application for energy started in 1960s; U.S. government funded the project that is called ASP (Aquatic Species Program) for algae technology development and further application in Hawaii, just after the oil crisis and mid-east war. Japanese government also held the project with idea using algae as the source for $\mathrm{CO}_{2}$ fixation and utilization in 1990 to 1996 . These projects provided valuable results, such as lipid production strains, aquatic culture system and principles for photo-bioreactor design. How to grow algae in large-scale aquaculture system and make the economic balance become the main topics for algae related energy application in early 21st century [10].

In recent studies, the using algae likes other main objective to biomass energy is about to overcome low performance and increase the efficiency. In purpose of improving the efficiency effectively, those algae needed to be treated or pretreated before used in energy system or transform into other energy phase. However, the algal biodiesel production has shown that lipid extraction and harvesting procedures could jeopardize the environment and cost energy waste. Some studies use the fermentation, which is anaerobic reaction with a biological process in which sugars such as glucose, fructose, and sucrose are converted into cellular energy and thereby produce ethanol and carbon dioxide as metabolic waste products. Anaerobic digestion is a spontaneous process mediated by micro-organisms converting biomass into biogas, but it still needs more developed [11].

Biomass utilization is the trend for biomass energy related applications, thermochemical conversion is considered one of the promising routes, and these processes include gasification, pyrolysis, liquefaction and combustion. Combustion is high temperature chemical reaction between fuel and oxidant, and converted fuel to energy in the form of heat in the gas
Table 1 The lipid concentration in microalgae.

\begin{tabular}{ll}
\hline Microalgae species & Lipid (\% dry weight) \\
\hline Monallanthus salina & $>20$ \\
Nannochloropsis sp.(fresh water) & $20-35$ \\
Nannochloropsis sp.(sea water) & $31-68$ \\
Neochloris oleoabundans & $35-54$ \\
Botryococcus braunii & $25-75$ \\
Chlorella sp. & $28-32$ \\
Crypthecodinium cohnii & 20 \\
Cylindrotheca sp. & $16-37$ \\
Dunaliella primolecta & 23 \\
Isochrysis sp. & $25-33$ \\
Nitzschia sp. & $45-47$ \\
Phaeodactylum tricornutum & $20-30$ \\
\hline
\end{tabular}

Refs. [3-9]

phase. Recently the microalgae energy-related researches focus on pyrolysis, such as bio-diesel. However, only a few studies about the microalgae in combustion behaviors, and mostly studied the Chlorella species. These studies analyzed the microalgae in different oxygen concentrations and $\mathrm{N}_{2} / \mathrm{O}_{2}$ ratio in TGA (thermogravimtric analysis) [12, 13]. In 2014, the Lopez-Gonzalez [14] reported that microalgae (Chlorella. vulgaris, Nannochloropsis gaditana and Scenedesmus almeriensis kinetic and analyzed in TGA-MS-DSC) are potential biomass for combustion application. In this study, we analyze the two different microalgae in TGA and calorific meter to provide the further information and potential development for combustion application in the future.

\section{Materials and Methods}

In order to analyze the microalgae potential for biomass energy and its primary heat property in combustion system, we selected two species of microalgae based on their specific specialties in energy applications and analyzed in calorific meter and TGA.

\subsection{Materials \& Biomass Selection}

Microalgae have been studied for decades, and used in energy application that depends on its property and composition. The chemical composition will be 
Calorific Meter for the Biomass Energy Application

important for using in energy related researches. However, we also have to consider the quantity and potential in biomass energy. Therefore, in this study we selected two different species algae that have been used in multi-applications and well known by the general consumers. Recently, Chlorella $V$. has been chosen as the raw material for producing bio-diesel, and Spirulina is used as the nutrient supplement. The two species of microalgae powder (Fig. 1) are from Taiwan Chlorella Manufacturing Company, and the microalgae powder uses wildly in food, nutrient supplements, cosmetic/medicine and fishery aquaculture. Macro-algae, Laminariaceae is from local supermarket in Kumamoto City.

\subsection{Calorific Value Detection}

The calorific value analysis method covers the determination of the gross calorific value of a prepared analysis sample of solid forms of biomass by the bomb calorimeter method. The calorific value, or heat of combustion, is a measure of the energy available from the microalgae. Calorific value is determined in this method by burning a weighed analysis sample in an oxygen bomb calorimeter under controlled conditions. The calorific meter is from SHIMADZU Corp., model: CA-4J.

\subsection{TGA}

TGA is used model type, "Setaram SETSYS Evolution TGA-1600C". The microalgae powder samples have to be stayed in oven $\left(40^{\circ} \mathrm{C}\right)$ over night before the testing. The starting temperature is $90^{\circ} \mathrm{C}$ in

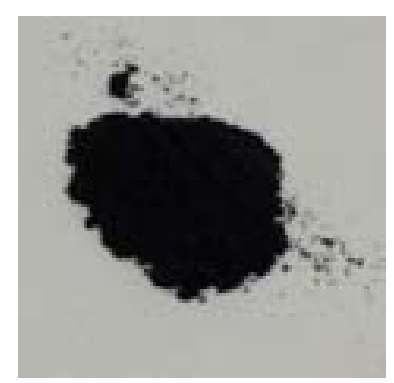

(a) Chlorella V.

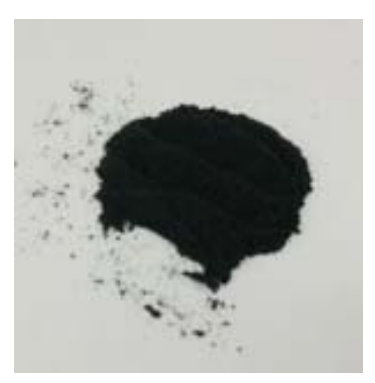

(b) Spirulina
Fig. 1 Microalgae powder samples from Taiwan Chlorella Manufacturing Company.

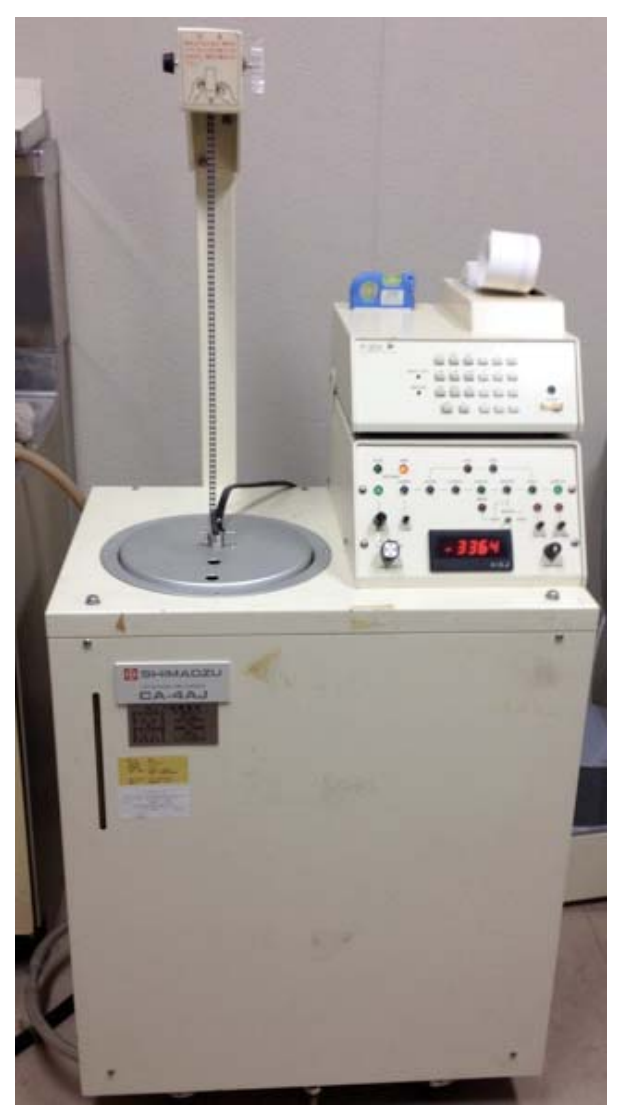

(a)

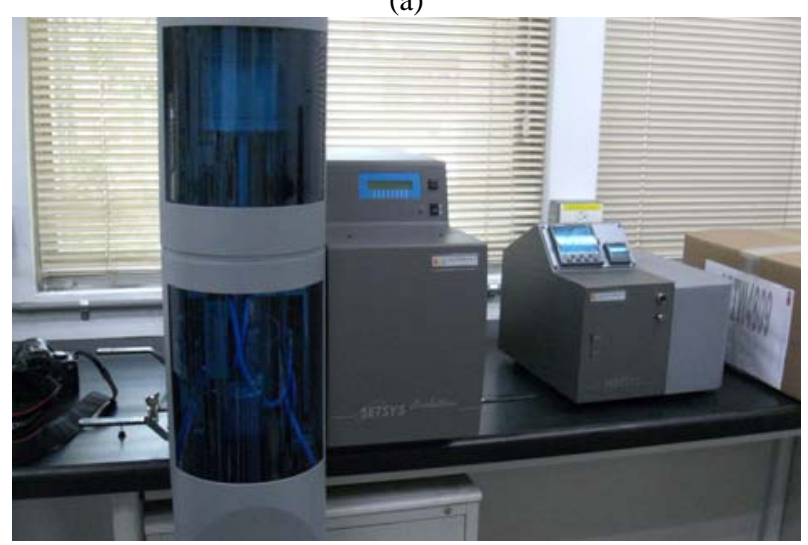

(b)

Fig. 2 (a) Calorific meter and (b) TGA.

30 min to remove the moisture and water in samples, and increasing $50{ }^{\circ} \mathrm{C} / \mathrm{min}$ until the temperature reached $900^{\circ} \mathrm{C}$.

\section{Results}

The microalgae samples were tested in Kumamoto University (Japan) for calorific values and TGA in ITRI (Industrial Technology Research Institute, Taiwan). 


\subsection{Microalgae Calorific Value}

Each sample had been dried out of moisture and tested for its calorific value. The results show as in Table 2, the calorific value in Chlorella and Spirulina are near 5,000 Kcal/KG. As we know that calorific values from fossil fuel and vege-oil are over 6,000 $\mathrm{Kcal} / \mathrm{KG}$ and higher than the calorific value from microalgae. Coal was also tested for the reference as fossil fuel.

The calorific value in microalgae is higher than wood waste, and lower than oil waste and other crop food source biomass materials. The calorific values from these two species of microalgae are near 5,000 $\mathrm{Kcal} / \mathrm{KG}$, and Chlorella is higher than Spirulina. Macro algae, Laminariaceae, the calorific value is lower than microalgae and wood waste. Compared to other biomass materials, the calorific values form microalgae are only higher than wood waste but lower than fossil fuel, too. None of them is higher than fossil fuel (6,548 Kcal/KG).

\subsection{Chlorella V. and Spirulina in TGA}

The major components in microalgae are $\mathrm{H}_{2} \mathrm{O}$, lipid, protein and the most of all, cellulose. The TGA results show as in Fig. 3, the samples decreased rapidly after the temperature reached $300{ }^{\circ} \mathrm{C}$ and $80 \%$ of the sample had been burned out after $900^{\circ} \mathrm{C}$.

\section{Discussions}

The calorific value results show that the potential of microalgae to be the material for biomass energy and TGA results are used to characterize the behavior in combustion system. Macro algae might need more enhance treatment or mix with other biomass materials to use in energy application. According to this study, the calorific value in microalgae is higher than wood waste, but still lower than fossil fuel (Table

Table 2 The Calorific values from microalgae and other biomass materials and fossil fuel.

\begin{tabular}{lllll}
\hline & $\mathrm{J} / \mathrm{g}$ & Kcal/KG & Type & Ref. \\
\hline Chlorella. & $21,174.5$ & $5,057.4$ & Non-food & This study \\
Spirulina & $20,866.3$ & $4,983.8$ & Non-food & This study \\
Laminariaceae & $11,665.5$ & $2,786.3$ & Food & This study \\
Coal & $28,665.6$ & $6,846.7$ & Fossil fuel & This study \\
Diesel & $42,000 \sim 49,500$ & & Fossil fuel & {$[15]$} \\
Coconut & $35,000 \sim 38,100$ & & Food & {$[15]$} \\
Soybean & $38,310 \sim 39,760$ & & Food & {$[15]$} \\
Wood Waste & 19,450 & $4,645.6$ & Waste & {$[16]$} \\
Vege-Oil & 33,700 & $8,049.1$ & Waste & {$[16]$} \\
\hline
\end{tabular}

$1 \mathrm{Kcal} / \mathrm{KG}=4.1868 \mathrm{KJ} / \mathrm{KG}$
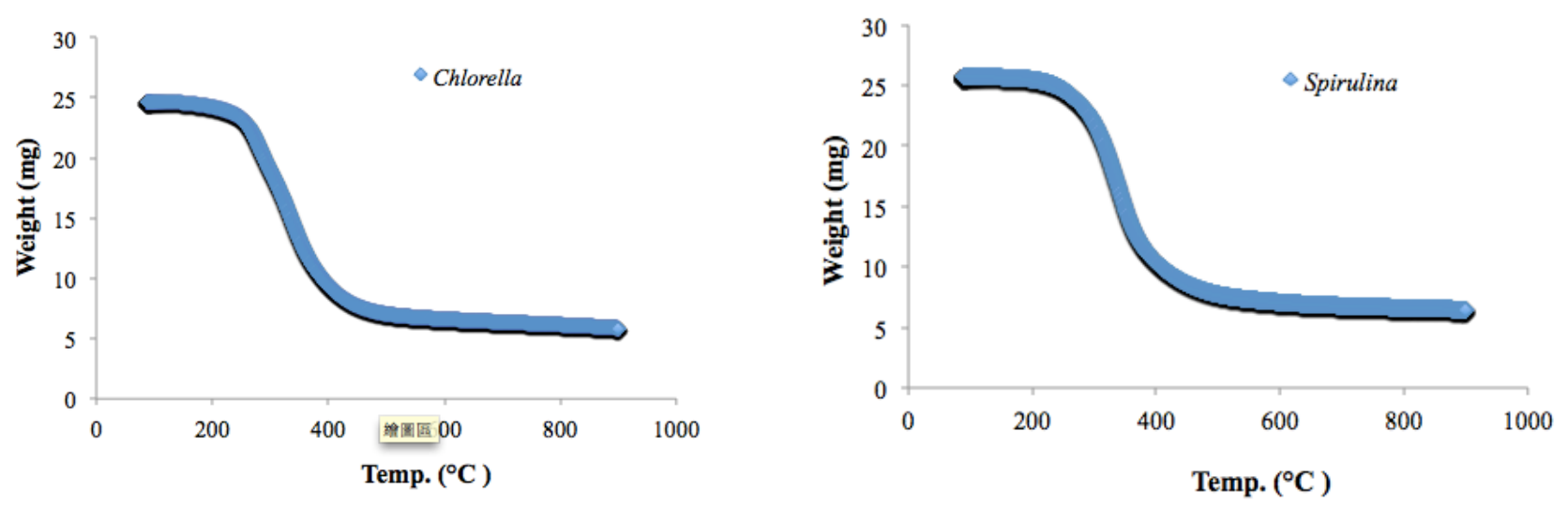

Fig. 3 Microalgae ((a) Chlorella and (b) Spirulina) weight changing from $90{ }^{\circ} \mathrm{C}$ to $900{ }^{\circ} \mathrm{C}$ in $\mathrm{TGA}$. 
2). This type of material needs to combine with other material to increase the calorific value and heat performance. As the TGA results show, the sample weight decreased rapidly after reached $300{ }^{\circ} \mathrm{C}$ and in $450{ }^{\circ} \mathrm{C}$, the decreased rate became slowly. Ref. [14] reported that Chlorella V. results showed in the TGA testing, the combustion would take two stages due to their chemical compositions: in the first stage, most of carbohydrate is combusted and in the second stage sulfur and nitrogen from protein degradation combusted. However, in this study, these two types of microalgae both decreased in linear, no second peak as the reference study. The results only prove the microalgae would be a potential material for combustion system and might need to test the microalgae in TGA-MS for the chemical release with temperature rising. The calorific value and TGA results show that, the microalgae has great potential for biomass energy application, and it uses as a great material in combustion system.

\section{Conclusions}

We analyzed two kinds of microalgae and one kind of Macro algae for their calorific value in calorific meter and the heat behaviors from microalgae in TGA. The microalgae calorific values are not able to complete fossil fuel or food source biomass material, but they are higher than wood waste. The main propose for third generation biofuel is using non-food source material (1st generation biofuel) and enhance the efficiency to above the 2nd generation biofuel. Microalgae with the advantage as the non-food, high lipid contents and high growth rate, could be used for the biomass energy application. Most of the microalgae-energy related researches are focusing on biodiesel or bioethanol, which might over use chemical and damaging the environment. In this study, the results would be used as the reference materials for microalgae using as biomass material in combustion. The microalgae might not be able to complete the fossil fuel and it still needs to combine with other materials, such as vege-oil, to enhance the calorific value. Algae and biomass energy related technologies still have a huge space for improvement and microalgae related researches would be even better optimized in the near future.

\section{References}

[1] Lau, L. C., Lee, K. T., and Mohamed, A. R. 2012. “Global Warming Mitigation and Renewable Energy Policy Development from the Kyoto Protocol to the Copenhagen Accord-A Comment.” Renewable and Sustainable Energy Reviews 16: 5280-4.

[2] Sims, R., Taylor, M., Saddler, J., and Mabee, W. 2008. "From 1st to 2nd Generation Biofuel Technologies: An Overview of Current Industry and R \& D Activities.” IEA Report.

[3] Chisti, Y. 2008. "Biodiesel from Microalgae." Biotechnology Advances 25: 294-306.

[4] Illman, A. M., Scragg, A. H., and Shales, S. W. 2000. "Increase in Chlorella Strains Calorific Values When Grown in Low Nitrogen Medium.” Enzyme Microbial Technology 27: 631-5.

[5] Nigam, P. S., and Singh, A. 2011. "Production of Liquid Biofuels from Renewable Resources.” Progress Energy Combustion Science 37: 52-68.

[6] Pulz, O. 2001. "Photobioreactors: Production Systems for Phototrophic Microorganisms.” Apply Microbiology Biotechnology 57: 287-93.

[7] Ras, M., Lardon, L., Bruno, S., Bernet, N., and Steyer, J. P. 2011. "Experimental Study on a Coupled Process of Production and Anaerobic Digestion of Chlorella Vulgaris.” Bioresource Technology 102: 200-6.

[8] Ratledge, C. 2004. "Fatty Acid Biosynthesis in Microorganisms Being Used for Single Cell Oil Production.” Biochimie 86: 807-15.

[9] Rocha, J. M. S., Garcia, J. E. C., and Henriques M. H. F. 2003. "Growth Aspects of the Marine Microalgae Nannochloropsis Gaditana." Biomolecular Engineering 20: 237-42.

[10] Scragg, A. H., Spiller, L., and Morrison, J. 2003. “The Effect of 2,4-Dichlorophenol on the Microalga Chlorella VT-1.” Enzyme Microbial Technology 2 (5): 616-22.

[11] Wijffels, R. H., and Barbosa, M. J. 2010. "An Outlook on Microalgal Biofuels.” Science 379: 796-9.

[12] Tang, Y., Ma, X., and Lai, Z. 2011. “Thermogravimetric Analysis of the Combustion of Microalgae and Microalgae Blended with Waste in $\mathrm{N}_{2} / \mathrm{O}_{2}$ and $\mathrm{CO}_{2} / \mathrm{O}_{2}$ Atmospheres." Bioresource Technology 102: 1879-85.

[13] Pane, L., Franceschi, E., De Nuccio, L., and Carli, A. 2001. "Applications of Thermal Analysis on the Marine 
phytoplankton, Tetraselmis suecica.” Journal of Thermal Analysis and Calorimetry 66: 145-54.

[14] López-González, D., Fernandez-Lopez, M., Valverde, J. L., and Sanchez-Silva, L. 2014. "Kinetic Analysis and Thermal Characterization of the Microalgae Combustion Process by Thermal Analysis Coupled to Mass Spectrometry.” Applied Energy 114: 227-37.

[15] Sadeghinezhad, E., Kazi, S. N., Badarudin, A., Oon, C. S., Zubir, M. N. M., and Mohammad, M. 2013. “A
Comprehensive Review of Bio-diesel as Alternative Fuel for Compression Ignition Engines.” Renewable and Sustainable Energy Reviews 28: 410-24.

[16] Chen, A. P., Basha, R. H., and Torii, S. 2014. "Classification of Biomass Based on Its Role of Combustion for Sustainable and Renewable Source of Energy Using Proximate and Ultimate Analysis.” International Journal of Earth Science \& Engineering 7: 136-42. 